\title{
Production of Lipopeptide Biosurfactant by a Marine Nesterenkonia sp. and Its Application in Food Industry
}

\author{
George S. Kiran ${ }^{*}$, Sethu Priyadharsini', Arya Sajayan ${ }^{1}$, Gopal B. Priyadharsini ${ }^{1}$, \\ Navya Poulose ${ }^{1}$ and Joseph Selvin ${ }^{2 *}$
}

${ }^{1}$ Department of Food Science and Technology, Pondicherry University, Puducherry, India, ${ }^{2}$ Department of Microbiology,

School of Life Sciences, Pondicherry University, Puducherry, India

\section{OPEN ACCESS}

Edited by: Giovanna Suzzi,

University of Teramo, Italy

Reviewed by: Marcia Nitschke,

University of São Paulo, Brazil

Thavasimuthu Citarasu,

Centre for Marine Science

and Technology, India

*Correspondence:

George S. Kiran

seghalkiran@gmail.com

kiran.mib@pondiuni.edu.in

Joseph Selvin

josephselvinss@gmail.com

Specialty section: This article was submitted to

Food Microbiology,

a section of the journa

Frontiers in Microbiology

Received: 19 March 2017 Accepted: 06 June 2017

Published: 28 June 2017

Citation:

Kiran GS, Priyadharsini S, Sajayan A,

Priyadharsini GB, Poulose N and

Selvin J (2017) Production

of Lipopeptide Biosurfactant by a Marine Nesterenkonia sp. and Its

Application in Food Industry.

Front. Microbiol. 8:1138.

doi: 10.3389/fmicb.2017.01138
Biosurfactants are smart biomolecules which have wide spread application in medicines, processed foods, cosmetics as well as in bioremediation. In food industry, biosurfactants are used as emulsion stabilizing agents, antiadhesives, and antimicrobial/antibiofilm agents. Nowadays biosurfactant demands in industries has increased tremendously and therefore new bacterial strains are being explored for large scale production of biosurfactants. In this study, an actinobacterial strain MSA31 was isolated from a marine sponge Fasciospongia cavernosa which showed high activity in biosurfactant screening assays such as drop collapsing, oil displacement, lipase and emulsification. Lipopeptide produced by MSA31 was found to be thermostable which was evident in differential scanning calorimetry analysis. The spectral data obtained in the Fourier transform infrared spectroscopy showed the presence of aliphatic groups combined with peptide moiety which is a characteristic feature of lipopeptides. The stability index of lipopeptide MSA31 revealed "halo-alkali and thermal tolerant biosurfactant" which can be used in the food industry. Microtiter plate assay showed $125 \mu \mathrm{g} / \mathrm{ml}$ of lipopeptide was effective in reducing the biofilm formation activity of pathogenic multidrug resistant Staphylococcus aureus. The confocal laser scanning microscopic images provided further evidences that lipopeptide MSA31 was an effective antibiofilm agent. The antioxidant activity of lipopeptide MSA31 may be due to the presence of unsaturated fatty acid present in the molecule. The brine shrimp cytotoxicity assay showed lipopeptide MSA31 was non-toxic and can be used as food additives. Incorporation of lipopeptide MSA31 in muffin showed improved organoleptic qualities compared to positive and negative control. This study provides a valuable input for this lipopeptide to be used in food industry as an effective emulsifier, with good antioxidant activity and as a protective agent against $S$. aureus.

Keywords: marine actinomycetes, lipopeptides, biosurfactant, antibiofilm, bioemulsifier

\section{INTRODUCTION}

Marine sponges are the reservoir of dense and unique marine microbial communities. The sponge tissue is a microbial niche which provides favorable conditions for the abundant growth of marine microorganisms. About $40 \%$ of sponge biomass comprises of complex microbial communities (Selvin et al., 2010). Actinomycetes are most abundant bacterial genera comprising about $20 \%$ 
of microbiome in some marine sponges (Montalvo et al., 2005; Gandhimathi et al., 2008). The metabolites derived from sponge associated actinomycetes show a wide range of biological activities which include antibacterial, antifungal, antiparasitic, antimalarial, immunomodulatory, anti-inflammatory, antioxidant, and anticancer properties (Selvin and Lipton, 2004; Bull and Stach, 2007; Pimentel-Elardo et al., 2010; Abdelmohsen et al., 2012; Blunt et al., 2013). Sponge associated actinomycetes were first reported biosurfactant producers among the group "actinomycetales" (Gandhimathi et al., 2009). Biosurfactants and bioemulsifier production has been increased in recent years as they were important green compounds which showed application in medicines, processed foods, cosmetics, and environmental cleaning (Kiran et al., 2010b).

Biosurfactants are compounds which have high surface tension reducing property along with emulsification activity whereas bioemulsifiers possess high emulsification activity with less or negligible surface tension reducing property. Biosurfactant and bioemulsifier production has increased in recent years as these biomolecules derived from actinomycetes showed tremendous application in medicine, processed foods, cosmetics and in bioremediation (Kiran et al., 2010b). Biosurfactants have multifunctional applications in food industry as emulsifiers, antiadhesives, and antimicrobial/antibiofilm agents. Biosurfactants are emulsion stabilizing agents, incorporated in food products to maintain the consistency, texture, solubilisation of fat globules, improve aroma, foaming and dispersing properties (Campos et al., 2013). Bioemulsifier is a natural food ingredient which can be used to improve the rheology of dough, increase the volume and emulsification of fat thus finds further applications in bakery and meat processing industry (Kourkoutas et al., 2004).

Considering the increased use of bioemulsifier in food industry, identification of new compounds with low or no toxicity and high emulsifying property has become essential Chemically synthesized surfactants are toxic whereas biosurfactants obtained from microbes are non-toxic and/or with least toxicity and they are highly stable at extreme temperature, $\mathrm{pH}$ and salinity. In food, rhamnolipid biosurfactant was used to improve the quality of the baked and confectionary products (Van Haesendonck and Vanzeveren, 2004). Incorporation of $0.10 \%$ rhamnolipid has been found to improve the texture and shelf life of muffin and croissants (Gandhi and Skebba, 2007). Bioemulsifier produced from marine Enterobacter cloacae has been used to enhance the viscosity of acidic food products (Shepherd et al., 1995; Iyer et al., 2006). Even though biosurfactants as bioemulsifiers have immense application in food industry, reports on their utilization in food industries are very limited.

In this study, a marine sponge associated actinomycetes Nesterenkonia sp. MSA31 was screened for biosurfactant production and was chemically characterized as lipopeptide derivative. The lipopeptide MSA31 showed no toxicity in brine shrimp cytotoxicity assay and acted as an antibiofilm agent against multi drug resistant Staphylococcus aureus. In this report, we demonstrate that incorporation of lipopeptide bioemulsifier in muffin preparation shows improved softness and its organoleptic quality.

\section{MATERIALS AND METHODS}

\section{Isolation and Screening of Actinomycetes}

The actinomycetes used in this study for biosurfactant production was isolated from a marine sponge Fasciospongia cavernosa collected by SCUBA diving at a depth of 10-15 $\mathrm{m}$ in Vizhinjam $8^{\circ} 22^{\prime} 45^{\prime \prime} \mathrm{N} 76^{\circ} 59^{\prime} 29^{\prime \prime} \mathrm{E}$ located in southwest coast of India. The sponge samples were immediately transported to the laboratory in ice box. Approximately $1 \mathrm{~cm}^{3}$ of the sponge tissue was excised using sterile scissors and washed extensively in sterile seawater. The sponge tissue was homogenized using a tissue homogenizer. The aliquot was serially diluted in sterile seawater and plated on various media as mentioned in our previous report (Gandhimathi et al., 2009). The isolates obtained were cultured on a minimal salt media containing $\mathrm{g} / \mathrm{L}$ of $\mathrm{KH}_{2} \mathrm{PO} 4$ $0.5 \mathrm{~g}, \mathrm{FeSO}_{4} 7 \mathrm{H}_{2} \mathrm{O} 0.1 \mathrm{~g}, \mathrm{Na}_{2} \mathrm{CO}_{3} 0.2 \mathrm{~g}$, L-asparagine $0.1 \mathrm{~g}$, $\mathrm{MgSO}_{4} 0.1 \mathrm{~g}$, yeast extract $1 \mathrm{~g}$ and $\mathrm{NaCl} 1 \mathrm{~g}, \mathrm{pH}$. After $144 \mathrm{~h}$ of incubation, the culture media were centrifuged at $14,000 \mathrm{rpm}$ for $20 \mathrm{~min}$ (Eppendorf). The filtrate obtained was screened on various screening assays including drop collapsing (Jain et al., 1991), oil displacement (Morikawa et al., 2000), lipase (Kiran et al., 2010b), haemolytic activity (Kiran et al., 2010b), surface tension measurement (dynamic tensiometer), and emulsification index (Paraszkiewicz et al., 1992). The emulsification index was determined using cell free supernatant (CFS) and sunflower oil (Goldwinner ${ }^{\circledR}$ ) as substrate (1:1), the mixture was vortexed for $60 \mathrm{~s}$ and stability of the formed emulsion was determined after $24 \mathrm{~h}$.

\section{Identification of Biosurfactant Producer}

The genomic DNA of MSA31 was isolated by $\mathrm{CTAB} / \mathrm{NaCl}$ method. Universal $16 \mathrm{~S}$ rRNA eubacterial primer (5'-GAGTTTG ATCCTGGCTCAG-3'; 5'-AGAAAGGAGGTGATCCAGCC-3') was used for the amplification of DNA. The 16S rRNA gene sequence obtained from the producers was compared with other bacterial sequences by using NCBI BLASTn (Altschul et al., 1990, 1997) for their pair wise identities. Multiple alignments of these sequences were carried out by Clustal W 1.83 version of $\mathrm{EBI}^{1}$ with 0.5 transition weight. Phylogenetic trees were constructed in MEGA 7 version ${ }^{2}$ using Maximum Parsimony (MP) method.

\section{Extraction and Purification of Biosurfactant}

The isolate MSA31 was inoculated into $1 \mathrm{~L}$ of production media composed of minimal salt media enriched with $10 \mathrm{~g}$ olive oil, $10 \mathrm{~g}$ ammonium nitrate and $19 \mathrm{~g} \mathrm{NaCl}$ and incubated at $28^{\circ} \mathrm{C}$ for $144 \mathrm{~h}$ with agitation of $180 \mathrm{rpm}$. After incubation, the CFS was obtained by centrifugation at $14,000 \mathrm{rpm}$ for $20 \mathrm{~min}$ at $4^{\circ} \mathrm{C}$ (Eppendorf). The supernatant was acidified to $\mathrm{pH} 2.0$ with $0.1 \mathrm{~N} \mathrm{HCl}$ and allowed to form precipitate by incubating overnight at $4^{\circ} \mathrm{C}$. The acid precipitate was collected by centrifugation at $12,000 \mathrm{rpm}$ for $30 \mathrm{~min}, 4^{\circ} \mathrm{C}$.

\footnotetext{
${ }^{1}$ www.ebi.ac.uk/cgi-bin/clustalw/

${ }^{2}$ www.megasoftware.net
} 
The precipitated biosurfactant was washed several times with sterile distilled water and the $\mathrm{pH}$ was adjusted to 7.0 using 0.1 $\mathrm{N} \mathrm{NaOH}$. The precipitate was resuspended in sterile distilled water and solvent optimization was performed by adding equal volume of extraction solvents such as methanol, ethyl acetate, diethyl ether and dichloromethane $(\mathrm{v} / \mathrm{v})$. The resultant aliquot was concentrated to dryness in a rotary vacuum evaporator (Yamato). The solvent extract with high emulsification activity was further purified using column chromatography on silica gel (60-120 mesh) with step wise elution with methanol and water ranging from 65 to $100 \%(\mathrm{v} / \mathrm{v})$ at a flow rate of $0.5 \mathrm{ml} / \mathrm{min}$ at room temperature $\left(27^{\circ} \mathrm{C}\right)$. The purified fraction was used for chemical characterization and identification of active molecule.

\section{Chemical Characterization of Biosurfactant Compound}

The active fraction was confirmed by the emulsification activity and the purity was checked by TLC. The TLC fractionation was performed using the solvent system for the separation of biomolecules which include proteins ( $n$-butanol: acetic acid: water 45:35:20), carbohydrates (chloroform: acetic acid: water 50:30:20) and lipids (chloroform: methanol: water 60:30:10). The spots developed on the TLC plates were visualized by spraying of $50 \% \mathrm{H}_{2} \mathrm{SO}_{4}$ for carbohydrates and ninhydrin for amino acids. The TLC plates were exposed in an iodine chamber to visualize the lipid fractions (Kiran et al., 2010b). To determine the functional groups the purified active column fraction was lyophilised in a lyophilizer (Yamato DC 400) and subjected to FT-IR analysis. The lyophilised active fraction was used for FTIR analysis on a Bruker IFS113v FTIR spectrometer, in the $4000-400 \mathrm{~cm}^{-1}$ spectral region at a resolution of $2 \mathrm{~cm}^{-1}$ and 50 scans. The lyophilized active fraction was investigated by using Gas chromatography (GC) (Perkin Elmer Autosystem XL GC-model Clarus-680, United States). For the structure prediction one dimensional ${ }^{1} \mathrm{H}$ NMR spectra were recorded by dissolving the biosurfactant at a concentration of $25 \mathrm{mg} / \mathrm{ml}^{-1}$ in deuterated DMSO and analyzed on a Bruker AVANCE III $500 \mathrm{MHz}$. C NMR was recorded on a solid state NMR (400 MHZ - JEOL-ECX-400).

\section{Stability of Biosurfactant}

The column purified fraction of biosurfactant was evaluated for its stability at different temperature, $\mathrm{pH}$ and salt concentrations. The stability assays were performed as per Kiran et al. (2010b). To determine the $\mathrm{pH}$ stability, the biosurfactant $0.4 \%$ $(\mathrm{w} / \mathrm{v})$ was dissolved in various $\mathrm{pH}$ ranges of buffer solutions which include $0.1 \mathrm{M}$ sodium acetate buffer ( $\mathrm{pH} 4.0-7.0)$ and $0.1 \mathrm{M}$ sodium phosphate buffer ( $\mathrm{pH}$ 8.0-9.0). The aliquot was incubated at $37^{\circ} \mathrm{C}$ for $1 \mathrm{~h}$ to determine $\mathrm{pH}$ stability based on emulsification index. Similarly, the biosurfactant $0.4 \%(\mathrm{w} / \mathrm{v})$ was dissolved in distilled water containing various concentrations of $\mathrm{NaCl}$ ranging between 1 and $12 \%$ and incubated at $37^{\circ} \mathrm{C}$ for $1 \mathrm{~h}$ to determine $\mathrm{NaCl}$ stability. Temperature stability was determined by incubating the biosurfactant at various temperatures ranging between 4 and $121^{\circ} \mathrm{C}$ for $1 \mathrm{~h}$, and then the stability of the compound was assessed based on the emulsification index.

\section{Thermal Gravimetric (TG) and Differential Scanning Calorimetric (DSC) Analysis}

Thermal Gravimetric and Differential Scanning Calorimetric of biosurfactant were performed and determined using TA instruments, Q600 SDT and Q20 DSC (Kiran et al., 2014). Approximately $3 \mathrm{mg}$ of sample was placed in an aluminum pan. The analysis was carried out over the temperature range from $0^{\circ} \mathrm{C}$ to $300^{\circ} \mathrm{C}$ at a rise in temperature of $10^{\circ} \mathrm{C} / \mathrm{min}$. The flow rate of the gas was set at $50 \mathrm{ml} / \mathrm{min}$.

\section{Antioxidant Activity}

Antioxidant activity of the biosurfactant from MSA31 was analyzed using 2,2-diphenyl-1-picryl hydrazyl (DPPH) radical scavenging assay (Turkmen et al., 2006) with necessary modifications. In this assay, $0.3 \mathrm{ml}$ containing different concentrations of biosurfactant between 0.5 and $6 \mathrm{mg} / \mathrm{ml}$ were added to $3.5 \mathrm{ml}$ of $99.5 \%$ ethanol containing DPPH (0.02 mM). The assay mixture was mixed well and incubated in dark at $25^{\circ} \mathrm{C}$ for $30 \mathrm{~min}$. Butylated hydroxytoluene (BHT) was used as the positive control, ethanol was set as blank and the assays were performed in triplicates. The process of decolourization was recorded at $520 \mathrm{~nm}$ using Shimadzu UV-VIS spectrophotometer. The percentage of radical scavenging was calculated using the following formula.

$$
\mathrm{AA}(\%)=\left[\left(\text { Abs. }_{\text {. control }}-\text { Abs. }_{\text {sample }}\right) / \text { Abs. }_{\text {control }}\right] \times 100
$$

\section{Brine Shrimp Cytotoxicity Assay}

The larvae of Artemia franciscana were obtained by decapsulation of sterile cysts as mentioned in Kiran et al. (2016). Briefly, the cysts were aerated in sterile seawater and oxygenated continuously using aerator pumps. After $24 \mathrm{~h}$ incubation at room temperature $\left(25-29^{\circ} \mathrm{C}\right)$, the freshly hatched nauplii (larvae) were collected by a micropipette. The nauplii were transferred into a 96 deep well plate with 10 nauplii per plate and different concentration of lipopeptide $(25-200 \mu \mathrm{g} / \mathrm{ml})$. The assay was performed in triplicates. Wells were examined under the binocular stereomicroscope (Optica) and the numbers of live and dead (non-motile) nauplii in each well were counted after $24 \mathrm{~h}$.

\section{Microtitre Plate Assay}

The clinical strains of $S$. aureus were collected from Jawaharlal Institute of Postgraduate Medical Education and Research (JIPMER), Puducherry. The antibiogram pattern was tested as per CLSI Guidelines: Clinical and Laboratory Standards Institute (2009) to select multi drug resistant strains. S. aureus biofilm was allowed to form on microtitre plate wells containing lipopeptide of varying concentration $(25 \mu \mathrm{g}-150 \mu \mathrm{g} / \mathrm{ml})$. The assay plates were prepared with $10 \mu \mathrm{l}$ of overnight culture of $S$. aureus diluted upto growth OD of 0.005 and was inoculated into $200 \mu \mathrm{l}$ of LuriaBertani broth. The plates were kept under static conditions for $72 \mathrm{~h}$ at $37^{\circ} \mathrm{C}$. After incubation the planktonic cells were removed by gentle pipetting, and the adhered cells were stained with $0.1 \%$ 
crystal violet and the amount of biofilm formation was quantified at $595 \mathrm{~nm}$ using a microplate reader (Labnics) (Kiran et al., 2010a).

\section{Antibiofilm Effect of Lipopeptide}

The antibiofilm activity of lipopeptide was visualized using confocal laser scanning microscopy (CLSM). Effective concentration of lipopeptide $125 \mu \mathrm{g} / \mathrm{ml}$ was added to the Erlenmeyer flask containing LB broth (test) and the flask without lipopeptide was set as the control. The sterile glass slide was immersed into the broth using a sterile forceps. The broth was then inoculated with $1 \mathrm{ml}$ of $S$. aureus overnight culture. After incubation at $37^{\circ} \mathrm{C}$ for $72 \mathrm{~h}$, the glass slide was washed with sterile distilled water and stained with Baclight kit (Invitrogen) following manufacturer's instructions. The glass slide was then stained with equal amount of solution $\mathrm{A}$ and solution B ( $3 \mathrm{ml}$ each), incubated for $15 \mathrm{~min}$ and observed under CLSM.

\section{Evaluation of Lipopeptide as a Fat Replacer in Muffin Preparation}

In order to evaluate the characteristics of lipopeptide on muffin preparation, the muffins were incorporated with varying concentration of lipopeptide between 0.50 and $1 \%$. The muffin batter formulation was carried out as per Zahn et al. (2010) with necessary modifications. The ingredients used for muffin preparation include $36.57 \%$ wheat flour, $11.7 \%$ margarine, $22.30 \%$ sugar, $17.18 \%$ whole egg, $11.7 \%$ skim milk, $0.52 \%$ baking powder, and $20 \%$ water (positive control batter for muffin preparation). In the test, baking powder and egg was replaced with $0.50-1 \%$ lipopeptide. The mixture without egg was set as the negative control. The formulated dough was placed in the muffin tray and baked in a preheated oven at $180^{\circ} \mathrm{C}$ for 20 min until the appearance of light brown color. The prepared muffin was sealed in an air tight container for the textural analysis.

\section{Textural Evaluation}

The textural characteristics of the muffin were analyzed using a Texture analyser (TA-HDplus, Stable Micro Systems, Surrey). The analyser was pre-tested at $1.0 \mathrm{~mm} / \mathrm{s}$, test speed at $3.0 \mathrm{~mm} / \mathrm{s}$ and post-speed at $10.0 \mathrm{~mm} / \mathrm{s}$, distance at $10 \mathrm{~mm}$ and $12.5 \mathrm{pps}$ data acquisition rate, $50 \mathrm{~kg}$ load cell and P75 probe was used to analyze the parameters such as hardness, gumminess, chewiness, springiness, and cohesiveness.

\section{Color Analysis of Muffin}

The color of muffin was analyzed by a Hunter colorimeter (Hunter Lab Associates Inc.) using $L^{*}, a^{*}, b^{*}$ color space. The $\mathrm{L}^{*}$ represents dark (0)/ light (100), while $\mathrm{a}^{*}$ and $\mathrm{b}^{*}$ represents red $(+a)$ to green $(+a)$ and yellow $(+b)$ to blue $(-b)$. The color was analyzed in triplicates and the mean was recorded.

\section{RESULTS AND DISCUSSION}

\section{Isolation, Screening, and Identification of Biosurfactant Producer}

A total of 33 morphologically distinct actinomycetes were isolated from the marine sponge $F$. cavernosa. All the isolates were screened for biosurfactant production. The isolate MSA31 was selected based on high emulsification activity (75\%) and surface tension reducing property of $34.6 \mathrm{mN} / \mathrm{m}$ with critical micelle concentration of $18.6 \mu \mathrm{g} / \mathrm{ml}$. The isolate MSA31 showed positive results in screening tests which include emulsification, drop collapsing and oil displacement. In drop collapsing test, a flat drop was observed whereas in oil displacement method, a clear diameter of $8 \mathrm{~mm}$ corresponding to the area of $64.24 \mathrm{~mm}^{2}$ was observed. Emulsification activity, surface tension and the screening tests confirmed the isolate MSA31 as a biosurfactant producer. The enzymes and bioactive molecules produced by the sponge associated bacteria are economically important due to their novelty and remain active even in extremophilic conditions such as elevated salt concentration, wide range of $\mathrm{pH}$, and higher temperatures. The isolate MSA31 grew optimally at increased salt concentration upto 5\% and $\mathrm{pH}$ 6-10. Similar $\mathrm{pH}$ tolerance was reported for Nesterenkonia alba which grow optimally at pH 9-10 (Luo et al., 2009). Delgado et al. (2006) reported that $N$. aethiopica, a moderately halophilic strain can grow at salt concentration up to $3 \%$ and $\mathrm{pH} 9.0$. There were a very few reports available on sponge associated actinobacteria for lipopeptide production (Gandhimathi et al., 2009; Kiran et al., 2010b). The PCR amplified KS (keto synthase) domain from the sponge associated actinobacteria envisages that the biosynthetic pathway of biosurfactants might have mediated through PKS (polyketide synthase) biosynthetic gene clusters (Selvin et al., 2016). Taxonomic affiliation based on the $16 \mathrm{~S}$ rRNA sequence of the isolate MSA31 was retrieved from the classifier program of RDPII (Ribosomal Database Project II). The 16S rRNA sequence of the isolate MSA31 was analyzed using a megablast tool of GenBank ${ }^{3}$. Based on the closet matches with Nesterenkonia strains, the isolate MSA31 was taxonomically identified as Nesterenkonia sp. (Figure 1). The closet representative of maximum homologous (98-99\%) sequences of each strains was obtained from seqmatch program of RDPII and was used for the construction of phylogenetic tree. The sequence obtained were deposited in genbank with accession number KY969127. A Nesterenkonia sp. isolated from Aran Bidgol lake (Iran) was used for the production of halophilic $\alpha$-amylase with possible application in starch processing industries, baking, brewing, textile, and distillery industries (Shafiei et al., 2012).

\section{Characterization of Biosurfactant}

Among the various solvents used for extraction, ethyl acetate extract showed highest emulsification activity. The crude

${ }^{3}$ http://www.ncbi.nlm.nih.gov/ 


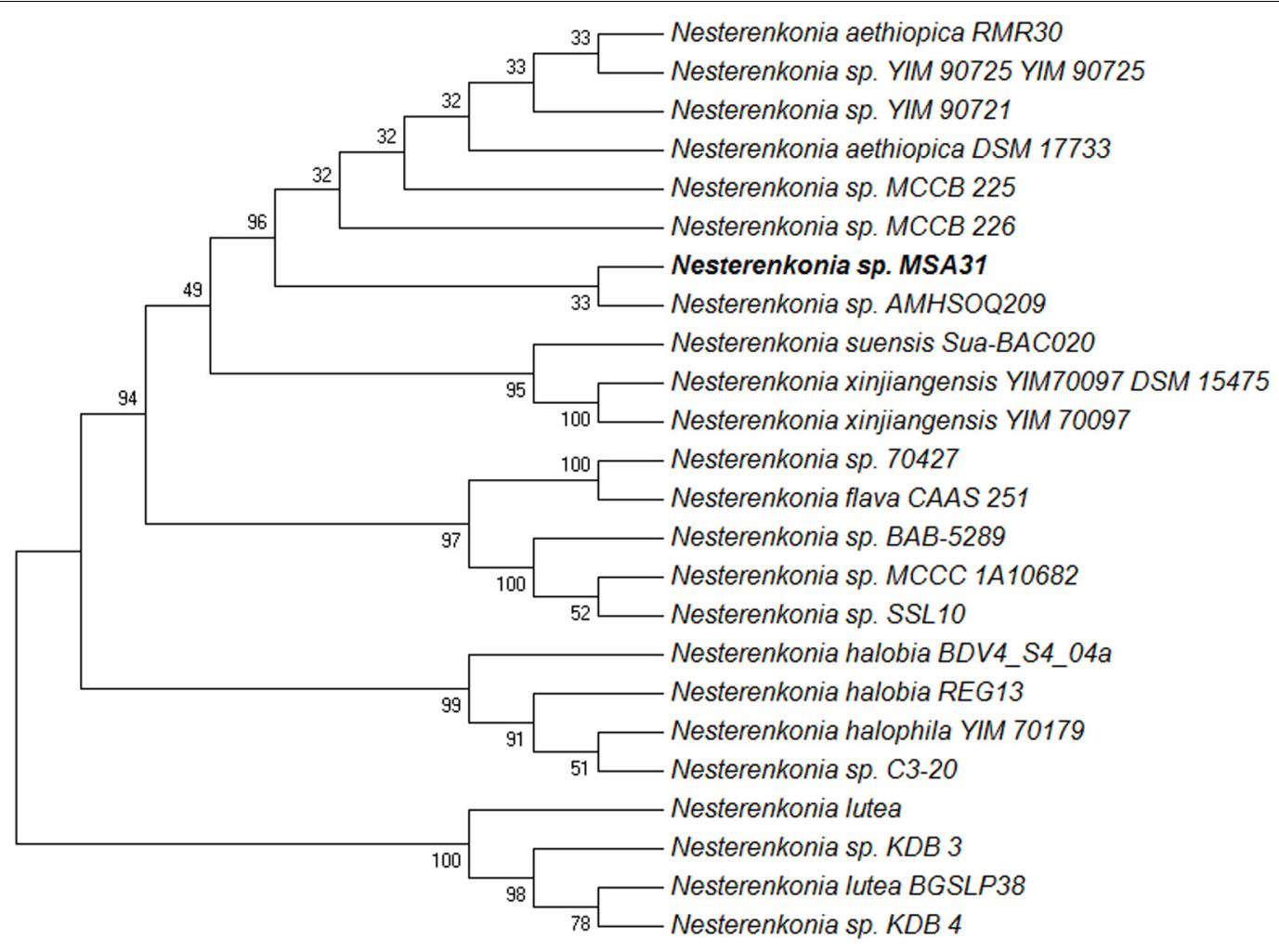

FIGURE 1 | Phylogenetic tree of MSA31 showing representatives of Nesterenkonia sp. The evolutionary history was inferred using the Maximum Parsimony method. Tree \#1 out of 9 most parsimonious trees (length $=89)$ is shown. The consistency index is $(0.821429)$, the retention index is $(0.938272)$, and the composite index is $0.780136(0.770723)$ for all sites and parsimony-informative sites (in parentheses). The percentage of replicate trees in which the associated taxa clustered together in the bootstrap test (1000 replicates) are shown next to the branches.

biosurfactant was purified in silica gel column chromatography with $80 \%$ methanol-water as eluting solvent. The active fractions collected from the column were checked for emulsification activity and analyzed in TLC to determine the purity of the compound. In the TLC plates, a yellow spot corresponding to the $\mathrm{Rf}$ value of 0.86 with chloroform: methanol: water (60:30:10) as the solvent system was identified as a biosurfactant (lipid) fraction. The FT-IR spectrum showed a strong broad peak at 3600-3200 $\mathrm{cm}^{-1}$ corresponding to the presence of hydrogen bonded $-\mathrm{OH}$ or $-\mathrm{NH}$ functional groups (Figure 2). The carboxylic groups at $1788 \mathrm{~cm}^{-1}$ and the sharp peak at $1630 \mathrm{~cm}^{-1}$ revealed the presence of amino acid zwitter ion $-\mathrm{C}=\mathrm{O}$ peak or amide carbonyl peak. The absorbance at $1531 \mathrm{~cm}^{-1}$ was attributed to the stretching vibrations of -NH bonds. Similar absorption spectra in FT-IR was reported for lipopeptide in the literature (de Faria et al., 2011; Ghribi and Ellouze-Chaabouni, 2011; Pereira et al., 2013). Weak absorbance signals at 1444 and $1396 \mathrm{~cm}^{-1}$ were due to the bending vibrations of $\mathrm{C}-\mathrm{H}$ bonds associated with alkyl chains. The peak appearing at $1055 \mathrm{~cm}^{-1}$ reveals another stretching frequency of C-O functional groups. The FT-IR spectra showed the presence of aliphatic groups combined with peptide moiety, a characteristic feature of lipopeptides. The GC-MS spectra showed the presence of aliphatic chain containing hexyl group.

\section{${ }^{1} \mathrm{H}$ NMR Analysis}

The ${ }^{1} \mathrm{H}$ NMR spectra showed broad multiplicity peaks between 8.3 and 7.5 ppm, which typify amino acid amide protons and confirm the presence of several amino acid residues in the molecule (Supplementary Figure S1). The aromatic phenyl group protons appeared as a multiplet in the range of 7.2 to $6.6 \mathrm{ppm}$ and it revealed that the aromatic groups were present in the molecule. Several peaks were observed in the region of 6.6-8.3, which indicates the presence of amino acid amide protons as reported by Pereira et al. (2013). The signals appearing in the region between 5.2 and $4.2 \mathrm{ppm}$ showed the presence of amino acid $\mathrm{H} \alpha$ resonance. The NMR peaks in the region of 5.2 were similar to the peaks reported earlier (Kowall et al., 1998; Liu et al., 2009). The peak at $3.2 \mathrm{ppm}$ to $2.9 \mathrm{ppm}$ revealed the protons attached with the acid functional group. The aliphatic $-\mathrm{CH}_{2}$ protons appeared in the range of 2.4 to $1.6 \mathrm{ppm}$. The singlet peaks appeared at 1.2 and $0.9 \mathrm{ppm}$ confirmed the presence of $-\mathrm{CH}_{3}$, which was attached with quaternary carbon.

\section{${ }^{13} \mathrm{C}$ NMR Spectra Analysis}

In the ${ }^{13} \mathrm{C} \mathrm{NMR}$ analysis the peak at $173 \mathrm{ppm}$ revealed an $-\mathrm{NH}_{2}$ group substituted quaternary carbon in the molecule, it may be due to presence of amino acid group in the molecule 


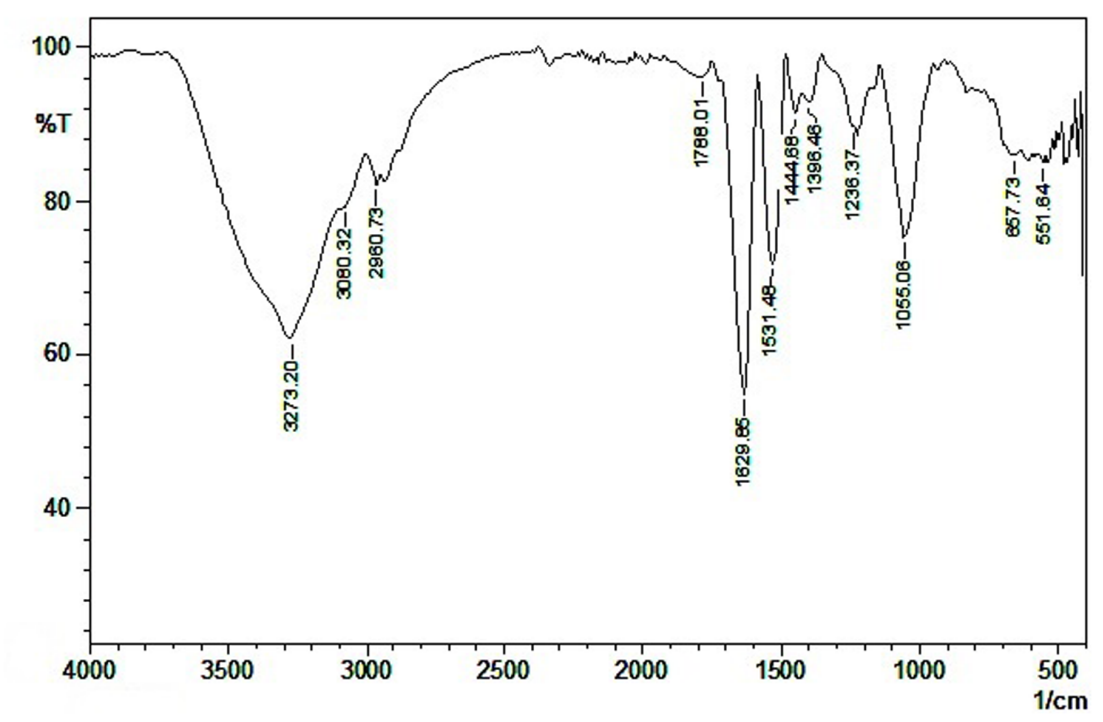

FIGURE 2 | Characterization of biosurfactant produced by MSA31 using FTIR.

(Supplementary Figure S1). The peaks at 155 ppm may be of an electronegative group attached to the aryl group, this reveals that molecule contains the electronegative groups. Peaks in the range of 136, 130, and 117 ppm showed the molecule contains aromatic groups. The peaks in the range of 73,58 , and $53 \mathrm{ppm}$ revealed the presence of aliphatic groups attached to electronegative atoms, trisubstituted or tetrasubstituted carbons. The chemical shift peaks in the range of $32,30,25,20,16$, $12 \mathrm{ppm}$ revealed the presence of several aliphatic groups present in the molecule. The spectral data revealed the compound produced by MSA31 was a lipopeptide moiety containing aromatic aminoacid and also revealed the presence of aliphatic groups.

\section{Stability of Biosurfactant}

Stability of biosurfactant is an important criteria required for its application in food industry. The lipopeptide based biosurfactant produced by MSA31 was found to be thermo-stable in all the temperature ranges tested (Figure 3A). Stability was maintained even after autoclaving at $121^{\circ} \mathrm{C}$ and there was no change in emulsification activity even at low temperature $4^{\circ} \mathrm{C}$. This property makes the lipopeptide from MSA31 suitable for ice cream and cosmetic industries. The emulsification activity (85\%) of biosurfactant MSA31 was retained at $10 \%$ salt concentration and at $\mathrm{pH}$ of 6.0-9.0.

In TGA analysis, due to loss of water molecule a change in the mass was observed at $150^{\circ} \mathrm{C}$ followed by second phase of degradation at $240^{\circ} \mathrm{C}$. Maximum degradation occurred at $260^{\circ} \mathrm{C}$ with weight loss of $50.725 \%$. The DSC data was used to determine the phase transitions of lipopeptide from 0 to $400^{\circ} \mathrm{C}$. The DSC thermogram showed exothermic peak of biosurfactant with crystallization temperature $\left(T_{\mathrm{c}}\right)$ of $80^{\circ} \mathrm{C}$ and the melting peaks were found at $240^{\circ} \mathrm{C}$ and $320^{\circ} \mathrm{C}$. The thermal stability of the lipopeptide based on TGA analysis is shown in Figure 3B. Lipopeptide produced by MSA31 was found to be thermostable as revealed by DSC analysis. Similar thermostable lipopeptide were produced by Nocardiopsis sp., Brevibacterium aureum, and Aneurinibacillus thermoaerophilus MK01 (Gandhimathi et al., 2009; Kiran et al., 2010b; Sharafi et al., 2014).

\section{Antioxidant Activity and Toxicity Evaluation DPPH Assay}

The DPPH activity of the lipopeptide from MSA31 was compared with the control BHT (Figure 4). A concentration dependent antioxidant activity of biosurfactant was recorded and highest activity was obtained at $6 \mathrm{mg} / \mathrm{ml}$. Antioxidant property is an important characteristics of food products as it reduces the risk of coronary heart diseases and is also effective against degenerative diseases. The scavenging activity of lipopeptide MSA31 at $6 \mathrm{mg} / \mathrm{ml}$ was $65 \%$ which was higher than the scavenging activity recorded for $P$. hubeiensis which showed $50.3 \%$ with $10 \mathrm{mg} / \mathrm{ml}$ of mannosyl erythritol lipid (Takahashi et al., 2012). The high antioxidant activity of lipopeptide MSA31 may be due to the presence of unsaturated fatty acid present in the molecule. The acute toxicity of the lipopeptide MSA31 was evaluated using the brine shrimp cytotoxicity assay. The assay results revealed the lipopeptide was non-toxic to the brine shrimp nauplii in all the concentrations tested (up to $200 \mu \mathrm{g} / \mathrm{ml}$ ). Previous reports related to the toxicity of lipopeptide were evaluated in in vivo toxicity assays in mice models which concluded that $2,000 \mathrm{mg} / \mathrm{kg}$ of body weight dose showed no mortality and normal behavioral indexes (Sahnoun et al., 2014). Park et al. (2006) reported that $\mathrm{LD}_{50}$ of surfactin in mice was above $2 \mathrm{~g} / \mathrm{kg}$. Biosurfactant produced by Serratia marcescens was administered to the mice orally at the dose of $5 \mathrm{~g} / \mathrm{kg}$ 

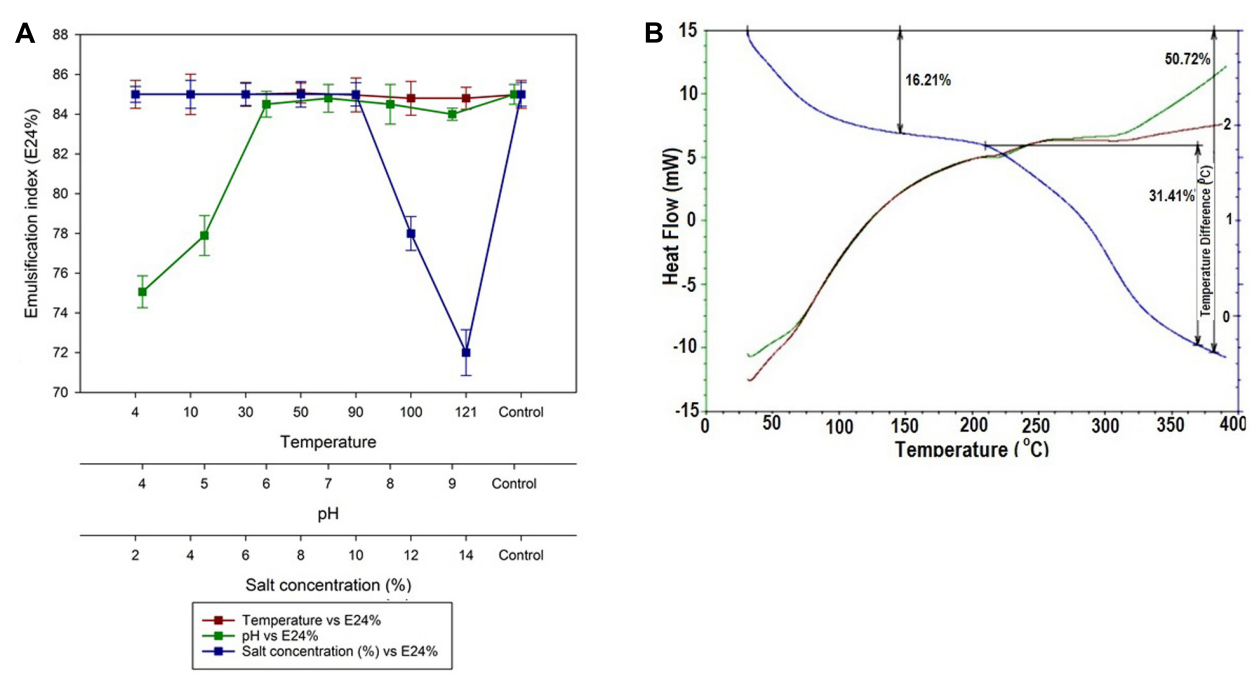

FIGURE 3 | (A) Stability of lipopeptide at increased temperature, $\mathrm{pH}$ and salt. The temperature stability is shown in (B) and the data indicates the compound was highly stable.

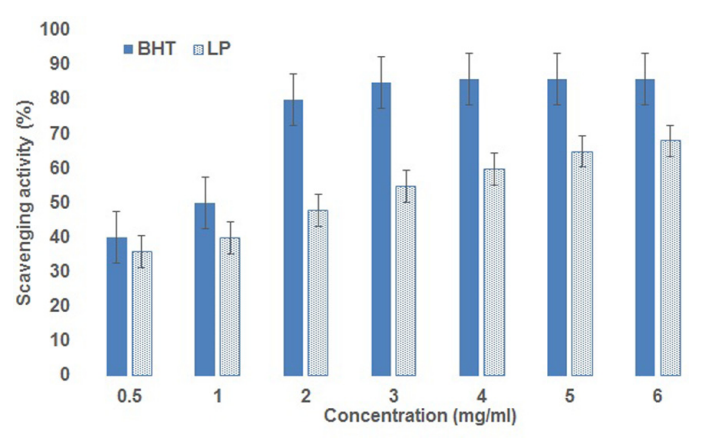

FIGURE 4 | Antioxidant activity of lipopeptide, the activity increases with the concentration of lipopeptide

and no toxic effect was noticed in the mice (Anyanwu et al., 2011). The available reports evidenced that lipopeptide and rhamnolipid biosurfactants in general were non-toxic biomolecules which can be used as food additives. According to Sahnoun et al. (2014) the lethal concentration of biosurfactant determined in the animal model was far higher than the threshold concentrations of food additives permitted by Food and Agricultural Organization and World Health Organization. In this study, brine shrimp cytotoxicity and phytotoxicity assays (Supplementary Figure S2) showed the non-toxic nature of lipopeptide biosurfactant.

\section{Antibiofilm Effect of Lipopeptide}

Microtiter plate assay showed lipopeptide MSA31 at a concentration of $125 \mu \mathrm{g} / \mathrm{ml}$ effectively reduced $90 \%$ of biofilm formed by $S$. aureus when compared to the control. It was observed that antibiofilm activity increases with increase in the concentration of the lipopeptide MSA31 (Figure 5A). The confocal microscope images evidenced that the lipopeptide was effective in controlling $S$. aureus biofilm formation (Figures 5B,C). The CLSM observation showed that the control biofilm was stained with green indicating live biofilm associated cells of $S$. aureus and the test biofilm was stained red indicating the dead cells of S. aureus. Microtiter plate assay and CLSM images showed lipopeptide at a concentration of $125 \mu \mathrm{g}$ effectively inhibited the biofilm of MDR pathogen S. aureus. Reports showed that lipopeptides from Bacillus sp. and Paenibacillus sp. were known to inhibit/disperse biofilms (Price et al., 2007; Kim et al., 2009; Quinn et al., 2012).

\section{Effect of Lipopeptide on Muffin Texture}

Textural property is an important parameter in determining the quality and sensory characteristics of the muffin. The lipopeptide incorporated muffin showed reduction in hardness, chewiness and gumminess when compared to positive and negative control (Table 1). Among the various concentrations of lipopeptide, $0.75 \%$ was found to be effective in enhancing the softness and overall quality of the muffin. Muffin prepared using $0.75 \%$ lipopeptide had higher level of springiness, when compared to the control. According to Tess et al. (2015), a high springiness value was associated with freshness and high quality of the muffin. Thus $0.75 \%$ lipopeptide incorporated muffin was in good quality with higher springiness values. Cohesiveness is defined as the compression energy required for breaking down the food product for swallowing. The muffin prepared with $0.75 \%$ lipopeptide showed increased cohesiveness and therefore less compression energy was required to break it down. This property was an indication of soft nature of muffin. Negative control showed higher value of chewiness indicating the hard nature of muffin and $0.75 \%$ of lipopeptide incorporated muffin showed very less value of chewiness indicating the soft nature of muffin. Overall, the muffin prepared using $0.75 \%$ lipopeptide showed decreased 

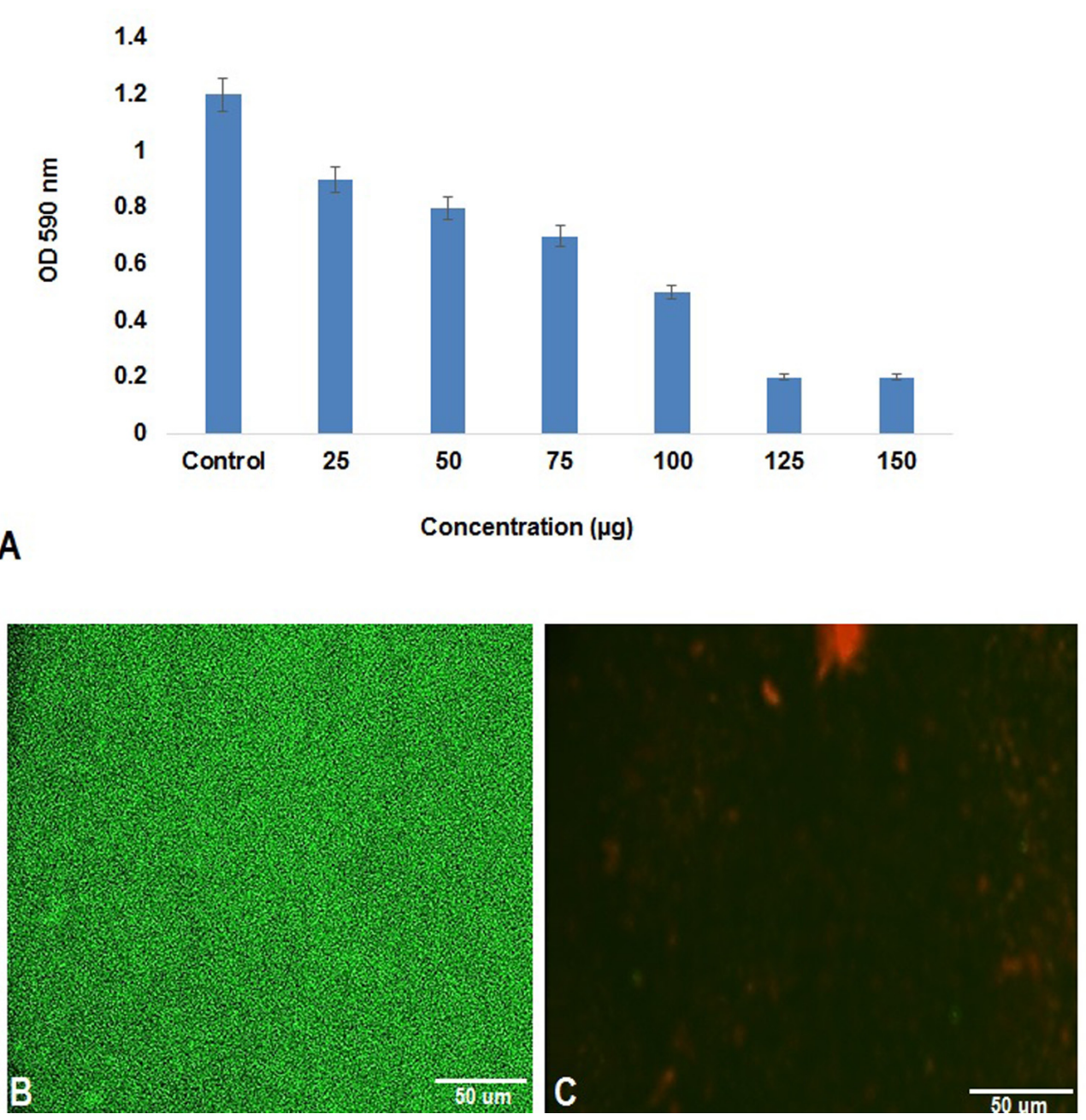

FIGURE 5 | Antibiofilm activity of lipopeptide MSA31 against MDR pathogen S. aureus. (A) Microtitre assay showing antibiofilm effect of Lipopeptide. (B) Is a control biofilm and (C) lipopeptide treated biofilm visualized by baclight staining.

hardness, chewiness and gumminess with increased springiness and cohesiveness.

\section{Color}

Color is an important factor to increase the appeal of the food products and is directly related to acceptance and taste (Chakraborty et al., 2015). The $\mathrm{L}^{*}, \mathrm{a}^{*}$, and $\mathrm{b}^{*}$ values of prepared muffins are given in Figure 6. The muffin prepared by using lipopeptide showed slight increase in the $b^{*}$ value which indicates the yellow colouration. The $b^{*}$ value of lipopeptide muffin was found to be 36 when compared to the negative and positive controls of 32.37 and 34.2 , respectively. The $\mathrm{L}^{*}$ value was higher in the negative control (without egg and baking powder), which indicates light color of the muffin and $\mathrm{a}^{*}$ value was found to be almost similar to the positive control and lipopeptide incorporated muffin. Normally in baked food products, changes in the natural color of the flour during baking is not uncommon due to Maillard reactions. The muffin prepared using lipopeptide MSA31 was light yellow in color as evident from $b^{*}$ value and the appeal was almost similar to the positive control. When Jambolan was incorporated into the muffin, the anthocyanin pigments in the Jambolan imparted dark color to the muffin (Singh et al., 2015).

\section{CONCLUSION}

In this study, actinobacterial strain Nesterenkonia sp. MSA31 was isolated from a marine sponge $F$. cavernosa. The strain MSA31 was found to be the highest biosurfactant producer among the 33 isolates screened. Based on the stability index, the lipopeptide MSA31 was characterized as "halo-alkali and thermal tolerant biosurfactant" which can be used as emulsifier and emulsion stabilizing agent in the food industry. The lipopeptide MSA31 was non-toxic, showed antibiofilm activity against a 
TABLE 1 | Shows texture analysis data of the muffin, the values represented are the mean of triplicate experiments.

\begin{tabular}{|c|c|c|c|c|c|}
\hline TPA parameters & Positive control & Negative control & $0.5 \%$ LP & $0.75 \%$ LP & $1 \%$ LP \\
\hline Hardness & $1978 \pm 2.0$ & $2999 \pm 3.60$ & $1675 \pm 4.0$ & $958 \pm 4.35$ & $1345 \pm 3.60$ \\
\hline Chewiness & $1128 \pm 3.0$ & $2150 \pm 2.64$ & $1115 \pm 3.0$ & $485 \pm 3.60$ & $900 \pm 4.58$ \\
\hline Gumminess & $1288 \pm 2.64$ & $1925 \pm 4.58$ & $1188 \pm 5.19$ & $515 \pm 3.46$ & $855 \pm 2.64$ \\
\hline Springiness & $0.99 \pm 0.18$ & $0.81 \pm 0.02$ & $0.96 \pm 0.12$ & $1.1 \pm 0.17$ & $0.98 \pm 0.08$ \\
\hline Cohesiveness & $0.66 \pm 0.05$ & $0.61 \pm 0.02$ & $0.65 \pm 0.05$ & $0.72 \pm 0.04$ & $0.67 \pm 0.78$ \\
\hline
\end{tabular}

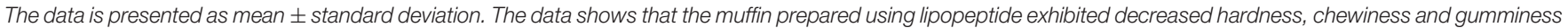
with increased springiness and cohesiveness values.
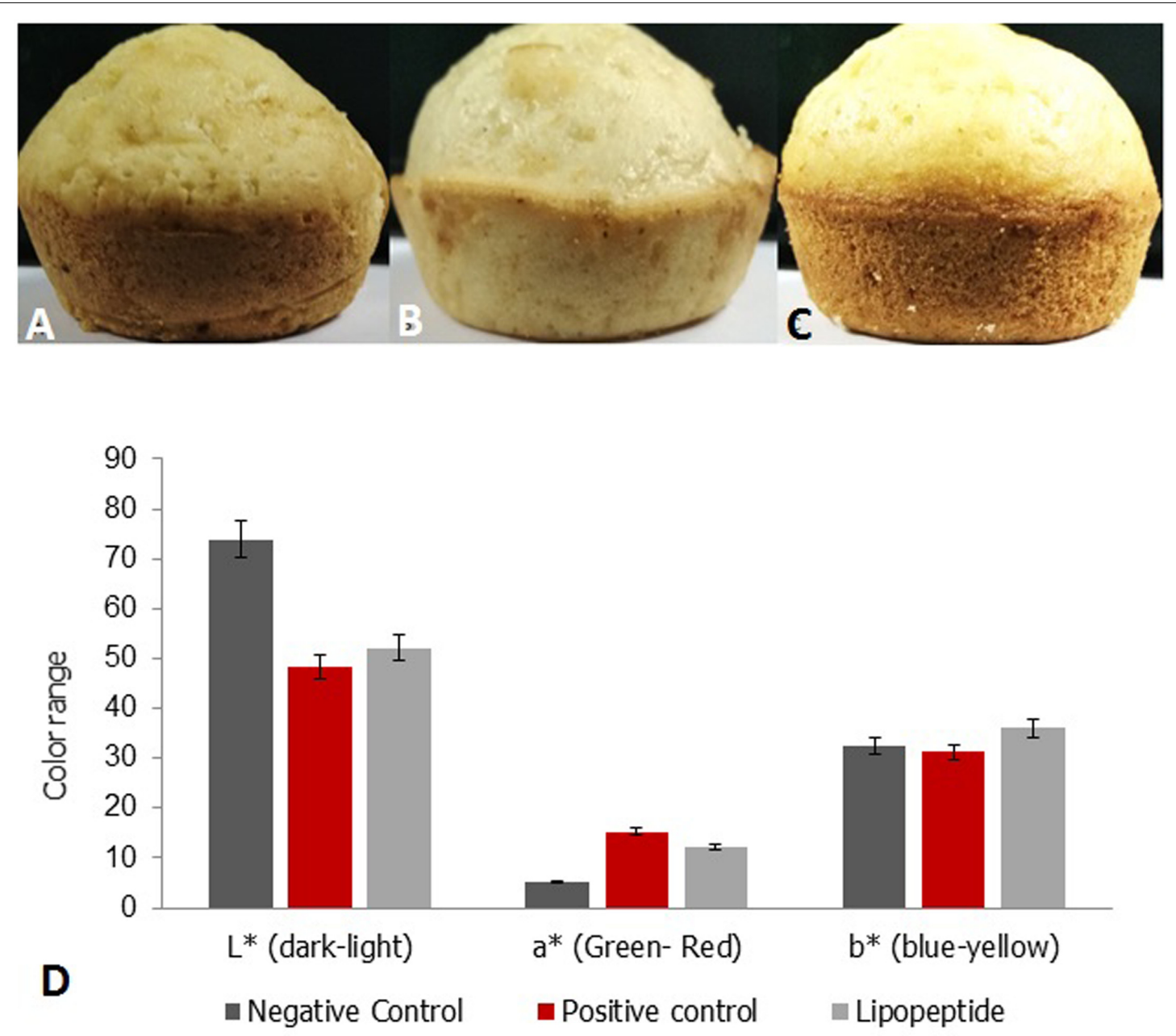

FIGURE 6 | Color analysis of muffin (A) Positive control muffin (egg and baking powder), (B) Negative control (C) muffin prepared using 0.75\% of lipopeptide. (D) Color analysis of muffin L* represent the color range of lightness to darkness as per the color scale standards of the HunterLab benchtop color measurement systems ( ${ }_{l}$ ColorFlex EZ), a* represents green $(-)$ to red $(+), b^{*}$ represents blue $(-)$ to yellow $(+)$. The addition of lipopeptide showed improved original color pattern of muffin to yellow color.

prominent food pathogen $S$. aureus. The emulsification property with antioxidant activity showed that the lipopeptide MSA31 can be highly beneficial to the food industry. Colors is an important factor to increase the appeal for the food products. The muffin prepared using lipopeptide showed light yellow in color, and the appeal was almost similar to the positive control. This study provided a new insight for the food industry as incorporation of lipopeptide emulsifier could improve the quality of food products with antioxidant activity as well as antibiofilm activity against S. aureus. 


\section{AUTHOR CONTRIBUTIONS}

AS, NP, SP, and GBP performed laboratory experiments and data analysis, GSK written the manuscript and JS designed and guided the work.

\section{ACKNOWLEDGMENTS}

GSK is thankful to the Department of Science and Technology for a project grant. JS is thankful to the DBT project on the

\section{REFERENCES}

Abdelmohsen, U. R., Szesny, M., Othman, E. M., Schirmeister, T., Grond, S., Stopper, H., et al. (2012). Antioxidant and anti-protease activities of diazepinomicin from the sponge-associated Micromonospora strain RV115. Mar. Drugs 10, 2208-2221. doi: 10.3390/md10102208

Altschul, S. F., Gish, W., Miller, W., Myers, E. W., and Lipman, D. J. (1990). Basic local alignment search tool. J. Mol. Biol. 215, 403-410. doi: 10.1016/S00222836(05)80360-2

Altschul, S. F., Madden, T. L., Schäffer, A. A., Zhang, J., Zhang, Z., Miller, W., et al. (1997). Gapped BLAST and PSI-BLAST: a new generation of protein database search programs. Nucleic Acids Res. 25, 3389-3402. doi: 10.1093/nar/25.17.3389

Anyanwu, C. U., Obi, S. K. C., and Okolo, B. N. (2011). Lipopeptide biosurfactant production by Serratia marcescens NSK-1 strain isolated from petroleumcontaminated soil. J. Appl. Sci. Res. 325, 79-87.

Blunt, J. W., Copp, B. R., Keyzers, R. A., Munro, M. H., and Prinsep, M. R. (2013). Marine natural products. Nat. Prod. Rep. 30, 237-323. doi: 10.1039/c2np20112g

Bull, A. T., and Stach, J. E. M. (2007). Marine actinobacteria: new opportunities for natural product search and discovery. Trends Microbiol. 15, 491-499. doi: 10.1016/j.tim.2007.10.004

Campos, J. M., Stamford, T. L. M., Sarubbo, L. A., Luna, J. M., Rufino, R. D., and Banat, I. M. (2013). Microbial biosurfactants as additives for food industries. Biotechnol. Prog. 29, 1097-1108. doi: 10.1002/btpr.1796

Chakraborty, P. S., Rao, H. N., and Mishra. (2015). Effect of combined high pressure-temperature treatments on color and nutritional quality attributes of pineapple (Ananas comosus L.) puree. Innov. Food Sci. Emerg. Technol. 28, 10-21. doi: 10.1016/j.ifset.2015.01.004

Clinical and Laboratory Standards Institute (2009). Performance Standards for Antimicrobial Susceptibility Testing: Twentieth Informational Supplement M100-S20. Wayne, PA: CLSI.

de Faria, A. F., Teodoro-Martinez, D. S., de Oliveira Barbosa, G. N., Vaz, B. G., Silva, I. S., Garcia, J. S., et al. (2011). Production and structural characterization of surfactin $\left(\mathrm{C}_{14} / \mathrm{Leu}_{7}\right)$ produced by Bacillus subtilis isolate LSFM-05 grown on raw glycerol from the biodiesel industry. Process Biochem. 46, 1951-1957. doi: 10.1016/j.procbio.2011.07.001

Delgado, O., Quillaguamán, J., Bakhtiar, S., Mattiasson, B., Gessesse, A., and HattiKaul, R. (2006). Nesterenkonia aethiopica sp. nov., an alkaliphilic, moderate halophile isolated from an Ethiopian soda lake. Int. J. Syst. Evol. Microbiol. 56, 1229-1232. doi: 10.1099/ijs.0.63633-0

Gandhi, N. R., and Skebba, V. L. P. (2007). Rhamnolipid compositions and related methods of use. U.S. Patent No WO 2007095258 A2. Washington, DC: U.S. Patent and Trademark Office.

Gandhimathi, R., Arunkumar, M., Selvin, J., Thangavelu, T., Sivaramakrishnan, S., Kiran, G. S., et al. (2008). Antimicrobial potential of sponge associated marine actinomycetes. J. Med. Mycol. 18, 16-22. doi: 10.1016/j.mycmed.2007.11.001

Gandhimathi, R., Kiran, G. S., Hema, T. A., Selvin, J., Raviji, T. R., and Shanmughapriya, S. (2009). Production and characterization of lipopeptide biosurfactant by a sponge-associated marine actinomycetes Nocardiopsis alba MSA10. Bioprocess Biosyst. Eng. 32, 825-835. doi: 10.1007/s00449-009-0309-x

Ghribi, D., and Ellouze-Chaabouni, S. (2011). Enhancement of Bacillus subtilis lipopeptide biosurfactants production through optimization of medium composition and adequate control of aeration. Biotechnol. Res. Int. 2011:653654. doi: $10.4061 / 2011 / 653654$ exploration of marine sponge microbiome. Finally, we thank Dr. E. Gnanamani, of Stanford University, for the interpretation of spectral data.

\section{SUPPLEMENTARY MATERIAL}

The Supplementary Material for this article can be found online at: http://journal.frontiersin.org/article/10.3389/fmicb. 2017.01138/full\#supplementary-material

Iyer, A., Mody, K., and Jha, B. (2006). Emulsifying properties of a marine bacterial exopolysaccharide. Enzyme Microb. Technol. 38, 220-222. doi: 10. 1016/j.enzmictec.2005.06.007

Jain, D. K., Collins-Thompson, D. L., Lee, H., and Trevors, J. T. (1991). A dropcollapsing test for screening surfactant-producing microorganisms. J. Microbiol. Methods 13, 271-279. doi: 10.1016/0167-7012(91)90064-W

Kim, K. M., Lee, J. Y., Kim, C. K., and Kang, J. S. (2009). Isolation and characterization of surfactin produced by Bacillus polyfermenticus KJS-2. Arch. Pharm. Res. 32, 711-715. doi: 10.1007/s12272-009-1509-2

Kiran, G. S., Lipton, A. N., Priyadharshini, S., Anitha, K., Suárez, L. E., Arasu, M. V., et al. (2014). Antiadhesive activity of poly-hydroxy butyrate biopolymer from a marine Brevibacterium casei MSI04 against shrimp pathogenic vibrios. Microb. Cell Fact. 13:114. doi: 10.1186/s12934-014-0114-3

Kiran, G. S., Priyadharshini, S., Dobson, A. D. W., Gnanamani, E., and Selvin, J. (2016). Degradation intermediates of polyhydroxy butyrate inhibits phenotypic expression of virulence factors and biofilm formation in luminescent Vibrio sp. PUGSK8. npj Biofilms Microbiomes 2:16002.

Kiran, G. S., Sabarathnam, B., and Selvin, J. (2010a). Biofilm disruption potential of a glycolipid biosurfactant from marine Brevibacterium casei. FEMS Immunol. Med. Microbiol. 59, 432-438. doi: 10.1111/j.1574-695X.2010.00698.x

Kiran, G. S., Thomas, T. A., Selvin, J., Sabarathnam, B., and Lipton, A. P. (2010b). Optimization and characterization of a new lipopeptide biosurfactant produced by marine Brevibacterium aureum MSA13 in solid state culture. Bioresour. Technol. 101, 2389-2396. doi: 10.1016/j.biortech.2009.11.023

Kourkoutas, Y., Bekatorou, A., Banat, I. M., Marchant, R., and Koutinas, A. A (2004). Immobilization technologies and support materials suitable in alcohol beverages production: a review. Food Microbiol. 21, 377-397. doi: 10.1016/j.fm. 2003.10.005

Kowall, M., Vater, J., Kluge, B., Stein, T., Franke, P., and Ziessow, D. (1998). Separation and characterization of surfactin isoforms produced by Bacillus subtilis OKB 105. J. Colloid Interface Sci. 204, 1-8. doi: 10.1006/jcis.1998.5558

Liu, X.-Y., Yang, S.-Z., and Mu, B.-Z. (2009). Production and characterization of a C 15-surfactin-O-methyl ester by a lipopeptide producing strain Bacillus subtilis HSO121. Process Biochem. 44, 1144-1151. doi: 10.1016/j.procbio.2009.06.014

Luo, H.-Y., Wang, Y.-R., Miao, L.-H., Yang, P.-L., Shi, P.-J., Fang, C.-X., et al. (2009). Nesterenkonia alba sp. nov., an alkaliphilic actinobacterium isolated from the black liquor treatment system of a cotton pulp mill. Int. J. Syst. Evol. Microbiol. 59, 863-868. doi: 10.1099/ijs.0.003376-0

Montalvo, N. F., Mohamed, N. M., Enticknap, J. J., and Hill, R. T. (2005). Novel actinobacteria from marine sponges. Antonie Van Leeuwenhoek 87, 29-36. doi: 10.1007/s10482-004-6536-x

Morikawa, M., Hirata, Y., and Imanaka, T. (2000). A study on the structurefunction relationship of lipopeptide biosurfactants. Biochim. Biophys. Acta 1488, 211-218. doi: 10.1016/S1388-1981(00)00124-4

Paraszkiewicz, K., Kanwal, A., and Dlugonski, J. (1992). Emulsifier production by steroid transforming filamentous fungus Curvularia lunata: growth and product characterization. J. Biotechnol. 92, 287-294. doi: 10.1016/S01681656(01)00376-5

Park, B. K., Lim, J. H., Hwang, Y. H., Kim, M. S., Song, I. B., Lee, H. G., et al. (2006). Acute oral toxicity of surfactin C in mice. J. Toxicol. Public Health 22, 453-458.

Pereira, J. F. B., Gudiña, E. J., Costa, R., Vitorino, R., Teixeira, J. A., Coutinho, J. A. P., et al. (2013). Optimization and characterization of biosurfactant 
production by Bacillus subtilis isolates towards microbial enhanced oil recovery applications. Fuel 111, 259-268. doi: 10.1016/j.fuel.2013.04.040

Pimentel-Elardo, S. M., Kozytska, S., Bugni, T. S., Ireland, C. M., Moll, H., and Hentschel, U. (2010). Anti-parasitic compounds from Streptomyces sp. strains isolated from Mediterranean sponges. Mar. Drugs. 8:373. doi: 10.3390/ $\operatorname{md} 8020373$

Price, N. P., Rooney, A. P., Swezey, J. L., Perry, E., and Cohan, F. M. (2007). Mass spectrometric analysis of lipopeptides from Bacillus strains isolated from diverse geographical locations. FEMS Microbiol. Lett. 271, 83-89. doi: 10.1111/ j.1574-6968.2007.00702.x

Quinn, G. A., Maloy, A. P., McClean, S., Carney, B., and Slater, J. W. (2012). Lipopeptide biosurfactants from Paenibacillus polymyxa inhibit single and mixed species biofilms. Biofouling 28, 1151-1166. doi: 10.1080/08927014.2012. 738292

Sahnoun, R., Mnif, I., Fetoui, H., Gdoura, R., Chaabouni, K., Makni-Ayadi, F., et al. (2014). Evaluation of Bacillus subtilis SPB1 lipopeptide biosurfactant toxicity towards mice. Int. J. Pept. Res. Ther. 20, 333-340. doi: 10.1007/s10989-014$9400-5$

Selvin, J., and Lipton, A. P. (2004). Dendrilla nigra, a marine sponge, as potential source of antibacterial substances for managing shrimp diseases. Aquaculture 236, 277-283. doi: 10.1016/j.aquaculture.2004.01.021

Selvin, J., Ninawe, A. S., Kiran, G. S., and Lipton, A. P. (2010). Sponge-microbial interactions: ecological implications and bioprospecting avenues. Crit. Rev. Microbiol. 36, 82-90. doi: 10.3109/10408410903397340

Selvin, J., Sathiyanarayanan, G., Lipton, A. N., Al-Dhabi, N. A., Arasu, M. V., and Kiran, G. S. (2016). Ketide synthase (KS) domain prediction and analysis of iterative type II PKS gene in marine sponge-associated actinobacteria producing biosurfactants and antimicrobial agents. Front. Microbiol. 7:68. doi: 10.3389/ fmicb. 2016.00063

Shafiei, M., Ziaee, A.-A., and Amoozegar, M. A. (2012). Purification and characterization of a halophilic $\alpha$-amylase with increased activity in the presence of organic solvents from the moderately halophilic Nesterenkonia sp. strain F. Extremophiles 16, 627-635. doi: 10.1007/s00792-012-0462-Z

Sharafi, H., Abdoli, M., Hajfarajollah, H., Samie, N., Alidoust, L., Abbasi, H., et al. (2014). First report of a lipopeptide biosurfactant from thermophilic bacterium Aneurinibacillus thermoaerophilus MK01 newly isolated from municipal landfill site. Appl. Biochem. Biotechnol. 173, 1236-1249. doi: 10.1007/s12010-0140928-9
Shepherd, R., Rockey, J., Shutherland, I. W., and Roller, S. (1995). Novel bioemulsifiers from microorganisms for use in foods. J. Biotechnol. 40, 207-217. doi: 10.1016/0168-1656(95)00053-S

Singh, J. P., Kaur, A., Shevkani, K., and Singh, N. (2015). Influence of jambolan (Syzygium cumini) and xanthan gum incorporation on the physicochemical, antioxidant and sensory properties of gluten-free eggless rice muffins. Int. J. Food Sci. Technol. 50, 1190-1197. doi: 10.1111/ijfs. 12764

Takahashi, M., Morita, T., Fukuoka, T., Imura, T., and Kitamoto, D. (2012). Glycolipid biosurfactants, mannosylerythritol lipids, show antioxidant and protective effects against $\mathrm{H}_{2} \mathrm{O}_{2}$-induced oxidative stress in cultured human skin fibroblasts. J. Oleo Sci. 61, 457-464. doi: 10.5650/jos. 61.457

Tess, M., Bhaduri, S., Ghatak, R., and Navder, K. P. (2015). Physical, textural and sensory characteristics of gluten-free muffins prepared with teff flour (eragrostis tef (zucc) trotter). J. Acad. Nutr. Diet. 9:A58.

Turkmen, N., Sari, F., and Velioglu, Y. S. (2006). Effects of extraction solvents on concentration and antioxidant activity of black and black mate tea polyphenols determined by ferrous tartrate and Folin-Ciocalteu methods. Food Chem. 99, 835-841. doi: 10.1016/j.foodchem.2005.08.034

Van Haesendonck, I. P. H., and Vanzeveren, E. C. A. (2004). Rhamnolipids in bakery products. U.S. Patent No W.O 2004/040984. Washington, DC: U.S. Patent and Trademark Office.

Zahn, S., Pepke, F., and Rohm, H. (2010). Effect of inulin as a fat replacer on texture and sensory properties of muffins. Int. J. Food Sci. Technol. 45, 2531-2537. doi: $10.1111 / j .1365-2621.2010 .02444 . x$

Conflict of Interest Statement: The authors declare that the research was conducted in the absence of any commercial or financial relationships that could be construed as a potential conflict of interest.

Copyright $\odot 2017$ Kiran, Priyadharsini, Sajayan, Priyadharsini, Poulose and Selvin. This is an open-access article distributed under the terms of the Creative Commons Attribution License (CC BY). The use, distribution or reproduction in other forums is permitted, provided the original author(s) or licensor are credited and that the original publication in this journal is cited, in accordance with accepted academic practice. No use, distribution or reproduction is permitted which does not comply with these terms. 